\title{
Temperature and pressure correlation for volume of gas hydrates with crystal structures sl and sll
}

\author{
Václav Vinš ${ }^{1, *}$, Andreas Jäger ${ }^{2}$, Sebastian Hielscher ${ }^{3}$, Roland $\operatorname{Span}^{3}$, Jan Hrubý ${ }^{1}$, and Cornelia Breitkopf ${ }^{2}$ \\ ${ }^{1}$ Institute of Thermomechanics of the CAS, Dolejškova 1402/5, Prague 8, 182 00, Czech Republic \\ ${ }^{2}$ Faculty of Mechanical Science and Engineering, Institute of Power Engineering, Technische Universität Dresden, Helmholtzstr. 14, \\ 01069 Dresden, Germany \\ ${ }^{3}$ Thermodynamics, Ruhr-Universität Bochum, Universitätsstr. 150, 44780 Bochum, Germany
}

\begin{abstract}
The temperature and pressure correlations for the volume of gas hydrates forming crystal structures SI and sII developed in previous study [Fluid Phase Equilib. 427 (2016) 268-281], focused on the modeling of pure gas hydrates relevant in CCS (carbon capture and storage), were revised and modified for the modeling of mixed hydrates in this study. A universal reference state at temperature of $273.15 \mathrm{~K}$ and pressure of $1 \mathrm{~Pa}$ is used in the new correlation. Coefficients for the thermal expansion together with the reference lattice parameter were simultaneously correlated to both the temperature data and the pressure data for the lattice parameter. A two-stage Levenberg Marquardt algorithm was employed for the parameter optimization. The pressure dependence described in terms of the bulk modulus remained unchanged compared to the original study. A constant value for the bulk modulus $B_{0}=10 \mathrm{GPa}$ was employed for all selected hydrate formers. The new correlation is in good agreement with the experimental data over wide temperature and pressure ranges from $0 \mathrm{~K}$ to $293 \mathrm{~K}$ and from 0 to $2000 \mathrm{MPa}$, respectively. Compared to the original correlation used for the modeling of pure gas hydrates the new correlation provides significantly better agreement with the experimental data for sI hydrates. The results of the new correlation are comparable to the results of the old correlation in case of sII hydrates. In addition, the new correlation is suitable for modeling of mixed hydrates.
\end{abstract}

\section{Introduction}

Our team is developing advanced models for thermophysical properties and phase behavior of fluid and solid systems relevant especially in carbon capture and storage (CCS) technologies. Most of the research is related to the modeling of gas hydrates, i.e. nonstoichiometric solid mixtures of water and various gases. Gas hydrates form so called clathrate structures, in which the hydrogen bonded water molecules build a crystal lattice with cavities containing the gas molecules [1]. Nowadays, gas hydrates are being investigated for several reasons, e.g., in the natural gas industry where they can cause pipeline blockage and other operational failures, as potential energy resource in the form of methane hydrates at the sea bottom or in relation to CCS technologies [2].

A new thermodynamic model for eight gas hydrate formers relevant mostly in CCS has recently been developed by our team [3-5]. The model is based on the van der Waals and Platteeuw approach [6] combined with highly accurate multiparameter equations of state for other phases than the hydrate [7,8]. Pure gas hydrates (water with a single gas species) of carbon dioxide, argon, oxygen, nitrogen, methane, carbon monoxide, ethane and propane can be predicted. An important advantage of the new model is that it is capable to predict a large variety of phase equilibria including those with pure solid phases, i.e. water ice and solid $\mathrm{CO}_{2}$ (dry ice), over wide temperature and pressure ranges with very good accuracy. Current activities are focused on a further extension of the pure hydrate model to hydrate mixtures. New complex phase equilibria algorithms, e.g., for three-phase and four-phase equilibria including both fluid and solid phases, are being developed for this purpose [9]. The pure hydrate model also needs to be modified such that it allows consistent modeling of gas hydrates and phase equilibria for various overall compositions of multicomponent aqueous mixtures. Among other, these modifications include a revision of the current correlation for the volume of gas hydrates.

In this study, the volume of gas hydrates forming cubic crystal structures of type sI and sII was investigated. The correlation for the lattice parameter employed in the pure hydrate model [3] was revised and modified such that it can be used for modeling of mixed hydrates. The reference conditions, i.e. the reference temperature $T_{0}$ and the reference pressure $p_{0}$, of the new volume correlation were set constant for both hydrate structures. Their values $T_{0}=273.15 \mathrm{~K}$ and $p_{0}=1 \mathrm{~Pa}$ are the same as the reference state for the Gibbs energy and enthalpy of hydrate employed in the model for mixed

* Corresponding author: vins.vaclav@seznam.cz

(C) The Authors, published by EDP Sciences. This is an open access article distributed under the terms of the Creative Commons Attribution License 4.0 (http://creativecommons.org/licenses/by/4.0/). 
hydrates [9]. Parameters of the new correlation for $11 \mathrm{sI}$ hydrates and 18 sII hydrates were correlated to the experimental data for both the temperature and the pressure dependence of the volume of gas hydrates using a two-stage Levenberg-Marquardt algorithm [10,11].

\section{Volume of gas hydrates}

In case of sI and sII hydrates, the volume can be determined from the lattice parameter $a$ of the unit cell as both structures form a cubic crystal system. In the hydrate models based on the van der Waals and Platteeuw approach [6], a hypothetical crystal structure called empty $\beta$-lattice is considered. This structure is formed by water molecules connected through hydrogen bonds and does not contain any gas (guest) molecules in the cavities. Knowing the lattice parameter and the number of water molecules $N_{\mathrm{w}}$ forming the unit cell, which is constant for each hydrate structure, the molar volume of the empty $\beta$-lattice can be determined as follows

$$
v^{\beta}\left[\mathrm{m}^{3} \mathrm{~mol}^{-1}\right]=\left(a[\AA] 10^{-10}\right)^{3} \frac{N_{\mathrm{AV}}\left[\mathrm{mol}^{-1}\right]}{N_{\mathrm{w}}},
$$

where $N_{\mathrm{AV}}$ stands for the Avogadro constant. The molar volume of hydrate can be calculated from the molar volume of the empty $\beta$-lattice in the following manner

$$
v=v^{\beta}\left(1+\sum_{i} v_{i} \sum_{J} \theta_{i, J}\right)^{-1} .
$$

In eq. (2), $v_{i}$ is the number of cavities of type $i$ divided by the number of water molecules in a unit cell $N_{\mathrm{w}}$ and $\theta_{i, J}$ is the fractional occupancy of cavity $i$ by guest molecule of type $J$. The cage occupancy $\theta_{i, J}$ needs to be determined from a convenient hydrate model, e.g., ref. $[3-5,12,13]$ or experimentally by diffraction methods [14-16].

Table 1. Summary of experimental data for the lattice parameter of sI hydrates

\begin{tabular}{rcccc}
\hline \multirow{2}{*}{ Guest } & \multicolumn{2}{c}{$\boldsymbol{T}$-data } & \multicolumn{2}{c}{$\boldsymbol{p}$-data } \\
\cline { 2 - 6 } & $\boldsymbol{N}$ & Ref. & $\boldsymbol{N}$ & Ref. \\
\hline $\mathrm{EtO}$ & 28 & {$[20,21]$} & - & \\
$\mathrm{CO}_{2}$ & 70 & {$[16,17$,} & - & \\
$\mathrm{C}_{2} \mathrm{H}_{6}$ & 11 & {$[17]$} & 10 & {$[27]$} \\
$0.85 \mathrm{CH}_{4}+0.15 \mathrm{CO}_{2}$ & 4 & {$[17]$} & - & \\
$0.47 \mathrm{CH}_{4}+0.53 \mathrm{C}_{2} \mathrm{H}_{6}$ & 2 & {$[17]$} & - & \\
$\mathrm{TMO}$ & 8 & {$[28]$} & - & \\
$\mathrm{CO}$ & 1 & {$[29]$} & - & \\
$\mathrm{H}_{2} \mathrm{~S}$ & 1 & {$[30,31]$} & - & \\
$\mathrm{CH}$ & 53 & {$[16,31-36]$} & 52 & {$[37,38]$} \\
$\mathrm{Xe}$ & 26 & {$[16,23,29]$} & 16 & {$[27,39]$} \\
$\mathrm{N}_{2}(\mathrm{sI})$ & - & & 6 & {$[14,15]$} \\
\hline
\end{tabular}

Tables 1 and 2 summarize experimental data points available for the lattice parameter of sI hydrates and sII hydrates, respectively. The annotation " $T$-data" denotes data for the temperature dependence of the lattice parameter measured at low pressures below $1 \mathrm{MPa}$; typically at atmospheric pressure. " $p$-data" marks data measured at higher pressures up to $3 \mathrm{GPa}$. Tables 1 and 2 contain also data for several binary mixed hydrates measured mostly by Hester et al. [17].

Table 2. Summary of experimental data for the lattice

\begin{tabular}{|c|c|c|c|c|}
\hline \multirow{2}{*}{ Guest } & \multicolumn{2}{|c|}{$T$ - data } & \multicolumn{2}{|c|}{$p$ - data } \\
\hline & $N$ & Ref. & $N$ & Ref. \\
\hline Air & 5 & {$[29,40]$} & 4 & {$[15]$} \\
\hline $\mathrm{Ar}$ & 1 & [29] & - & \\
\hline $\mathrm{Kr}$ & 3 & {$[30]$} & & \\
\hline $\mathrm{O}_{2}$ & 1 & {$[29]$} & 9 & {$[15]$} \\
\hline $\mathrm{N}_{2}$ & 18 & {$[16,29]$} & 18 & {$[14,15]$} \\
\hline TMO & 9 & {$[28]$} & - & \\
\hline $\mathrm{C}_{3} \mathrm{H}_{8}$ & 21 & {$[17,33,41]$} & - & \\
\hline $0.60 \mathrm{CH}_{4}+0.4 \mathrm{C}_{3} \mathrm{H}_{8}$ & 3 & {$[17]$} & - & \\
\hline $0.30 \mathrm{C}_{2} \mathrm{H}_{6}+0.7 \mathrm{C}_{3} \mathrm{H}_{8}$ & 5 & {$[17]$} & & \\
\hline $0.182 \mathrm{CO}_{2}+0.818 \mathrm{C}_{3} \mathrm{H}_{8}$ & 5 & [17] & & \\
\hline $0.876 \mathrm{CH}_{4}+0.124 \mathrm{i}-\mathrm{C}_{4} \mathrm{H}_{10}$ & 7 & [17] & & \\
\hline Natural gas & 3 & [17] & - & \\
\hline $0.95 \mathrm{CH}_{4}+0.05 \mathrm{C}_{5} \mathrm{H}_{10} \mathrm{O}$ & 10 & [17] & & \\
\hline THF & 18 & {$[21,42]$} & & \\
\hline $0.82 \mathrm{CH}_{4}+0.18 \mathrm{C}_{2} \mathrm{H}_{6}$ & 12 & [43] & & \\
\hline $\mathrm{THF}+\mathrm{H}_{2} \mathrm{~S}$ & 1 & {$[44]$} & & \\
\hline $\mathrm{THF}+\mathrm{Xe}$ & - & & 13 & [27] \\
\hline $\mathrm{CH}_{4}(\mathrm{sII})$ & - & & 13 & {$[45]$} \\
\hline
\end{tabular}
parameter of sII hydrates

\subsection{Correlations for the temperature dependence}

Most of the hydrate models, e.g., by Klauda and Sandler [46] or Martín and Peters [47], use correlations for the thermal expansion of lattice parameter determined by Tse et al. on the basis of their experimental measurements with ethylene oxide (EtO) hydrates for structure sI $[20,21]$

$$
a(T)=11.835+2.2173 \cdot 10^{-5} T+2.2415 \cdot 10^{-6} T^{2},
$$

and with tetrahydrofuran (THF) hydrates [21] for structure sII

$$
\begin{aligned}
a(T)= & 17.130+2.249 \cdot 10^{-4} T+ \\
& 2.013 \cdot 10^{-6} T^{2}-1.009 \cdot 10^{-9} T^{3}
\end{aligned} .
$$

Both correlations provide reasonable results over a wide temperature range from $20 \mathrm{~K}$ up to $260 \mathrm{~K}$. However, application of eqs. (3) and (4) to the modeling of various hydrates different from ethylene oxide and tetrahydrofuran represents a rather rough simplification. As it is shown later in Tables 5 and 6 in section 3.1, the lattice parameter at a given temperature and pressure may significantly vary for various hydrate formers. The reason is that the interactions between the guest molecules and the water cavities and subsequently the volume of the unit cell depend on the guest type. 
A universal and accurate correlation for thermal expansion of sI and sII hydrates was developed by Hester et al. [17]. Based on the literature data and their own experimental measurements for a large variety of hydrates including binary mixed hydrates, Hester et al. found out that the thermal expansion can be considered dependent only on the hydrate structure. Consequently, the temperature dependence of the relative lattice parameter $a / a_{0}$ can be universally described by the following function for all hydrates forming the same crystal structure.

$$
\frac{a(T)}{a_{0}}=\exp \left[\begin{array}{l}
\alpha_{1}\left(T-T_{0}\right)+ \\
\alpha_{2}\left(T-T_{0}\right)^{2}+\alpha_{3}\left(T-T_{0}\right)^{3}
\end{array}\right]
$$

In eq. (5), $a_{0}$ denotes the lattice parameter at the reference temperature $a\left(T_{0}\right)$. Introduction of the reference lattice parameter in eq. (5) made the correlation by Hester et al. universal for all sI and sII hydrates unlike the correlations by Tse et al. [20,21], eqs. (3) and (4), which are based solely on the data for two specific hydrates.

Hansen et al. [16] have recently measured new accurate data for the thermal expansion of hydrogenated and deuterated hydrates of $\mathrm{CO}_{2}, \mathrm{CH}_{4}, \mathrm{Xe}$ and $\mathrm{N}_{2}$ over wide temperature ranges from $10 \mathrm{~K}$ up to the stability limit around $280 \mathrm{~K}$. A high-pressure cell was used for the measurements at the temperatures above $200 \mathrm{~K}$. The data were correlated by polynomial fits of up to the forth order in case of $\mathrm{CO}_{2}, \mathrm{CH}_{4}$, and $\mathrm{N}_{2}$ hydrates. The data for Xe hydrates and for $\mathrm{CO}_{2}$ hydrates (for comparison) were correlated by Hansen et al. [16] by a modified Einstein model for thermal expansion.

$$
a(T)=a_{0}+\left(e_{0}+e_{1} T\right) /\left[\exp \left(\theta_{E} / T\right)-1\right]
$$

In eq. (6), $a_{0}$ is the lattice parameter at $0 \mathrm{~K}, e_{0}$ and $e_{1}$ are coefficients of the internal energy of the crystal, and $\theta_{\mathrm{E}}$ is a characteristic Einstein temperature. Correlation (6) provided better results only for Xe hydrates compared to the polynomial fits. Based on their new data, Hansen et al. [16] stated that the thermal expansion depends on the hydrate former and that a universal model for all hydrates forming the same crystal structure proposed by Hester et al. [17] can hardly be justified. On the other hand, major differences between the new data of Hansen et al. and the universal correlation (5) occur mostly in the high temperature region above approximately $220 \mathrm{~K}$. The correlation by Hester et al. [17] was based mostly on the low temperature data as the data above $230 \mathrm{~K}$ were rather limited at that time. As a consequence, results of correlation (5) by Hester et al. [17] are more or less pure extrapolation to temperatures above $230 \mathrm{~K}$. In this work, we employed the universal approach of Hester et al. [17], because the new temperature and pressure correlation for the volume of gas hydrates is intended for the modeling of various gas hydrates with large differences in the amount and quality of experimental data for the lattice parameter.

\subsection{Correlations for the pressure dependence}

The data situation for the pressure dependence of the lattice parameter corresponding to the isothermal compressibility of hydrates is significantly worse compared to the thermal expansion data; see the amount of data points and the number of references indicated with " $p$ - data" in Tables 1 and 2.

Most of the hydrate models use various quadratic or cubic functions of pressure in the correlations of hydrate volume, e.g., the correlation employed by Klauda and Sandler [46] based on the data for methane hydrates

$$
a(T, p)=\sqrt[3]{a(T)^{3}-8.006 \cdot 10^{-9} p+5.448 \cdot 10^{-12} p^{2}},
$$

where $a(T)$ can be obtained from eqs. (3) or (4) and $p$ denotes the pressure in $\mathrm{MPa}$. The main weakness of similar correlations is that they are valid over limited pressure ranges and their extrapolating behavior is rather questionable, e.g., the compressibility of hydrates can increase with increasing pressure or become negative at a certain pressure.

In the accurate model for natural gas hydrates by Ballard and Sloan [1,12], a constant compressibility $\kappa$ was considered.

$$
a(T, p)=a(T) \exp \left[-\kappa\left(p-p_{0}\right)\right]
$$

However, as it is discussed in our previous work [3], Ballard and Sloan correlated the compressibility mostly to the hydrate three-phase equilibrium data and not to the crystallographic data for the lattice parameter. Consequently, in the model of Ballard and Sloan [1,12] the compressibility was employed as a sort of correcting parameter improving the predictive ability of the hydrate model at high pressures. Values of $\kappa$ differ by several orders of magnitude for various hydrate formers in this case.

In our model for pure $\mathrm{CO}_{2}$ hydrates [13], a nonconstant compressibility was introduced.

$$
a(T, p)=a(T)\left[1-\frac{\kappa_{1}\left(p-p_{0}\right)}{1+\kappa_{2}\left(p-p_{0}\right)}\right] .
$$

The compressibility given by eq. (9) is monotonically decreasing to zero at an infinite pressure, which represents physically reasonable behavior. Nevertheless, fitting two parameters $\kappa_{1}$ and $\kappa_{2}$ for the compressibility of various hydrate formers appeared as rather difficult task according to unfavorable situation with the experimental data.

In our previous work [3-5] focused on the development of model for eight pure gas hydrates relevant in CCS, it was shown that the pressure dependence of the volume of sI and sII gas hydrates can be well described with the Murnaghan [18] equation of state for solids. The Murnaghan equation is a simplified version of the Birch-Murnaghan [19] equation, which is commonly used for the representation of experimental lattice parameter data. The Murnaghan equation considers a bulk modulus, i.e. the inverse value of the isothermal compressibility, that is linearly increasing with pressure.

$$
B(p)=B_{0}+B_{0}^{\prime} p=\frac{1}{\kappa(p)}
$$

In eq. (10), $B_{0}$ is the bulk modulus in $\mathrm{Pa}$ at zero pressure and $B_{0}^{\prime}$ is a constant bulk modulus derivative. 
The Murnaghan equation of state results in the following correlation for the pressure dependence of the lattice parameter

$$
a(T, p)=a\left(T, p_{0}\right)\left(\frac{B_{0}+B_{0}^{\prime} p}{B_{0}+B_{0}^{\prime} p_{0}}\right)^{\frac{-1}{3 B_{0}^{\prime}}}
$$

where the reference pressure $p_{0}$ is arbitrarily set to $1 \mathrm{~Pa}$ in this study. Based on the comparison of the Murnaghan equation and the Birch-Murnaghan equation, the bulk modulus derivative can usually be taken constant $B_{0}^{\prime}=4$. As it was shown in ref. [3], the pressure data available for hydrates forming structures sI and sII can be well correlated with a constant bulk modulus $B_{0}=10 \mathrm{GPa}$. This universal value is also used here.

\section{New correlation for the lattice parameter of sl and sll gas hydrates}

The new correlation for the lattice parameter intended for modeling mixed hydrates has the same mathematical form as the correlation for pure gas hydrates developed in the previous work [3]; see eq. (12). However, the values of the parameters $T_{0}, p_{0}, a_{0}$ and coefficients $\alpha_{1}$ to $\alpha_{3}$ are different for the pure hydrate model and the mixed hydrate model.

$$
\begin{aligned}
& a(T, p)=a_{0}\left(\frac{B_{0}+4 p}{B_{0}+4}\right)^{\frac{-1}{12}} \\
& \exp \left[\alpha_{1}\left(T-T_{0}\right)+\alpha_{2}\left(T-T_{0}\right)^{2}+\alpha_{3}\left(T-T_{0}\right)^{3}\right]
\end{aligned}
$$

The volume correlation employed in the pure hydrate model has several disadvantages making it inconvenient for the modeling of mixed hydrates. The correlation uses different values for the reference temperature $T_{0}$ for each hydrate structure. Moreover, the reference temperatures and the reference pressure differ from the reference state conditions of the water empty $\beta$ lattice at which the reference Gibbs energy and the reference enthalpy are given, i.e. $T_{0}^{\beta}=273.15 \mathrm{~K}$ and $p_{0}^{\beta}=1 \mathrm{~Pa}$; for more detail see ref. $[3-5,9]$. In the model of pure gas hydrates, the thermal expansion coefficients $\alpha_{1}$ to $\alpha_{3}$ were evaluated only from the lattice parameter data for $\mathrm{CO}_{2}$ hydrates in case of sI structure [13] and taken from Hester et al. [17] in case of sII structure. The $\mathrm{CO}_{2}$ correlation [13] and the correlation by Hester et al. [17] were evaluated solely from the temperature data. Main advantage of the new correlation (12) is that it can simultaneously be fitted to both the temperature and the pressure data. Consequently, all available data summarized in Tables 1 and 2 can be considered in the evaluation of the reference parameter $a_{0}$ and the thermal expansion coefficients $\alpha_{1}$ to $\alpha_{3}$ in the new correlation (12). As a result, the new correlation shall provide a more reliable and universal prediction for the lattice parameter of a large variety of SI and sII hydrates.

For the purpose of the new mixed hydrate model, a universal reference temperature $T_{0}=273.15 \mathrm{~K}$ and a universal reference pressure $p_{0}=1 \mathrm{~Pa}$ are proposed in eq. (12). The bulk modulus has a constant value of
$B_{0}=10 \cdot 10^{9} \mathrm{~Pa}$ for all the selected hydrates. Parameter $a_{0}$ and coefficients $\alpha_{1}$ to $\alpha_{3}$ were determined with the help of a two-stage Levenberg-Marquardt optimization algorithm $[10,11]$. The main algorithm optimizes values for the thermal expansion coefficients $\alpha_{1}$ to $\alpha_{3}$, which are universal for a given hydrate structure. For each iteration of the main algorithm, nested Levenberg-Marquardt algorithm optimizes the reference lattice parameter $a_{0}$ for each hydrate former. The nested algorithm is called $N$-times, where $N$ is the number of hydrate formers equal to 11 in case of sI hydrates and 18 in case of sII hydrates; see data summarized in Tables 1 and 2 . The Levenberg-Marquardt algorithm optimizes following objective function

$$
\sum_{i=1}^{N} w_{i}\left(a_{\mathrm{exp}, i}-a_{\mathrm{cor}, i}\right)^{2}=\min ,
$$

where $a_{\exp }$ is the experimental value and $a_{\text {cor }}$ is the correlated value of the lattice parameter. $w_{i}$ stands for the weight of the given experimental data point. For most data points, the weight was set to unity. The weight was reduced to 0.25 for the data measured with deuterated hydrates, i.e. with heavy water $\left(\mathrm{D}_{2} \mathrm{O}\right)$, and for high pressure data above $700 \mathrm{MPa}$. The data for deuterated hydrates by Hansen et al. [16] were not considered in the parameter optimization. The weight for the data taken from the molecular simulations for methane hydrates by Docherty et al. [36] was reduced down to 0.0001 .

Table 3 shows a comparison of the average deviation $\mathrm{AD}$ defined by eq. (14) and the absolute average deviation AAD given by eq. (15) for the correlation employed in the pure hydrate model [3] and for the new correlation. In case of sI hydrates, the new correlation provides significantly lower $\mathrm{AD}$ and $\mathrm{AAD}$. Main reason is that the new correlation was fitted to all available data, while the pure hydrate correlation was correlated only to the temperature dependence for $\mathrm{CO}_{2}$ hydrates. Results of both correlations are comparable in case of sII hydrates. The new correlation is slightly better.

$$
\begin{gathered}
\mathrm{AD}=\frac{1}{N} \sum_{i=1}^{N} a_{\mathrm{exp}, i}-a_{\mathrm{cor}, i} \\
\mathrm{AAD}=\frac{1}{N} \sum_{i=1}^{N}\left|a_{\mathrm{exp}, i}-a_{\mathrm{cor}, i}\right|
\end{gathered}
$$

Table 3. Number of experimental data, absolute deviation AD and average absolute deviation AAD for the correlation used in the model for pure gas hydrates [3] and the new correlation eq. (12)

\begin{tabular}{lcr}
\hline & Vinš et al. [3] & this study \\
\hline Structure sI & & \\
$N$ & 288 & \\
$\mathrm{AD} / \AA$ & -1.122 & -0.550 \\
$\mathrm{AAD} / \AA$ & 4.316 & 3.388 \\
$\mathrm{Structure} \mathrm{sII}$ & & \\
$N$ & 179 & \\
$\mathrm{AD} / \AA$ & -0.449 & -0.155 \\
$\mathrm{AAD} / \AA$ & 2.128 & 2.029 \\
\hline
\end{tabular}




\subsection{Final parameters}

Table 4 contains the final values for thermal expansion coefficients $\alpha_{1}$ to $\alpha_{3}$ for hydrate structures SI and sII. The reference temperature $T_{0}$ in eq. (12) equals $273.15 \mathrm{~K}$.

The optimized values for the reference lattice parameter $a_{0}$ are given in Table 5 for sI hydrates and in Table 6 for sII hydrates. The values are being used in the model for mixed hydrates [9].

Table 4. Thermal expansion coefficients for the lattice parameter of sI and sII gas hydrates correlated by eq. (12)

\begin{tabular}{lccc}
\hline Struct. & $\boldsymbol{\alpha}_{\mathbf{1}} / \mathbf{K}^{\mathbf{1}}$ & $\boldsymbol{\alpha}_{\mathbf{2}} / \mathbf{K}^{-\mathbf{2}}$ & $\boldsymbol{\alpha}_{\mathbf{3}} / \mathbf{K}^{-\mathbf{3}}$ \\
\hline sI & $8.416128 \cdot 10^{-5}$ & $7.141596 \cdot 10^{-8}$ & $-2.106472 \cdot 10^{-10}$ \\
sII & $7.988807 \cdot 10^{-5}$ & $1.686500 \cdot 10^{-7}$ & $1.363783 \cdot 10^{-10}$ \\
\hline
\end{tabular}

Table 5. Reference lattice parameter $a_{0}$ at $273.15 \mathrm{~K}$ and $1 \mathrm{~Pa}$ in eq. (12) for sI hydrates

\begin{tabular}{rl}
\hline \multicolumn{1}{l}{ Guest } & \multicolumn{1}{c}{$\boldsymbol{a}_{\mathbf{0}} / \AA$} \\
\hline $\mathrm{EtO}$ & 11.997604 \\
$\mathrm{CO}_{2}$ & 11.979675 \\
$\mathrm{C}_{2} \mathrm{H}_{6}$ & 12.067015 \\
$0.85 \mathrm{CH}_{4}+0.15 \mathrm{CO}_{2}$ & 11.978807 \\
$0.47 \mathrm{CH}_{4}+0.53 \mathrm{C}_{2} \mathrm{H}_{6}$ & 12.042290 \\
$\mathrm{TMO}^{2}$ & 12.138742 \\
$\mathrm{CO}$ & 12.017111 \\
$\mathrm{H}_{2} \mathrm{~S}$ & 12.082851 \\
$\mathrm{CH}$ & 11.970005 \\
$\mathrm{Xe}$ & 11.987297 \\
$\mathrm{~N}_{2}(\mathrm{sI})$ & 11.969756 \\
\hline
\end{tabular}

Table 6. Reference lattice parameter $a_{0}$ at $273.15 \mathrm{~K}$ and $1 \mathrm{~Pa}$ in eq. (12) for sII hydrates

\begin{tabular}{|c|c|}
\hline Guest & $a_{0} / \AA$ \\
\hline Air & 17.283598 \\
\hline $\mathrm{Ar}$ & 17.232725 \\
\hline $\mathrm{Kr}$ & 17.237294 \\
\hline $\mathrm{O}_{2}$ & 17.262769 \\
\hline $\mathrm{N}_{2}$ & 17.275606 \\
\hline TMO & 17.226661 \\
\hline $\mathrm{C}_{3} \mathrm{H}_{8}$ & 17.288930 \\
\hline $0.60 \mathrm{CH}_{4}+0.4 \mathrm{C}_{3} \mathrm{H}_{8}$ & 17.313328 \\
\hline $0.30 \mathrm{C}_{2} \mathrm{H}_{6}+0.7 \mathrm{C}_{3} \mathrm{H}_{8}$ & 17.276450 \\
\hline $0.182 \mathrm{CO}_{2}+0.818 \mathrm{C}_{3} \mathrm{H}_{8}$ & 17.327134 \\
\hline $0.876 \mathrm{CH}_{4}+0.124 \mathrm{i}-\mathrm{C}_{4} \mathrm{H}_{10}$ & 17.374086 \\
\hline Natural gas & 17.313652 \\
\hline $0.95 \mathrm{CH}_{4}+0.05 \mathrm{C}_{5} \mathrm{H}_{10} \mathrm{O}$ & 17.435520 \\
\hline THF & 17.334988 \\
\hline $0.82 \mathrm{CH}_{4}+0.18 \mathrm{C}_{2} \mathrm{H}_{6}$ & 17.284555 \\
\hline $\mathrm{THF}+\mathrm{H}_{2} \mathrm{~S}$ & 17.336587 \\
\hline $\mathrm{THF}+\mathrm{Xe}$ & 17.424193 \\
\hline $\mathrm{CH}_{4}(\mathrm{sII})$ & 17.277118 \\
\hline
\end{tabular}

\subsection{Results - temperature dependence}

Fig. 1 shows a comparison of the experimental data for the temperature dependence of the lattice parameter of sI hydrates with the correlation by Jäger et al. [13] used in the pure hydrate model [3-5] and the new correlation (12). The deviation of both correlations from the experimental data is provided in Fig. 2.

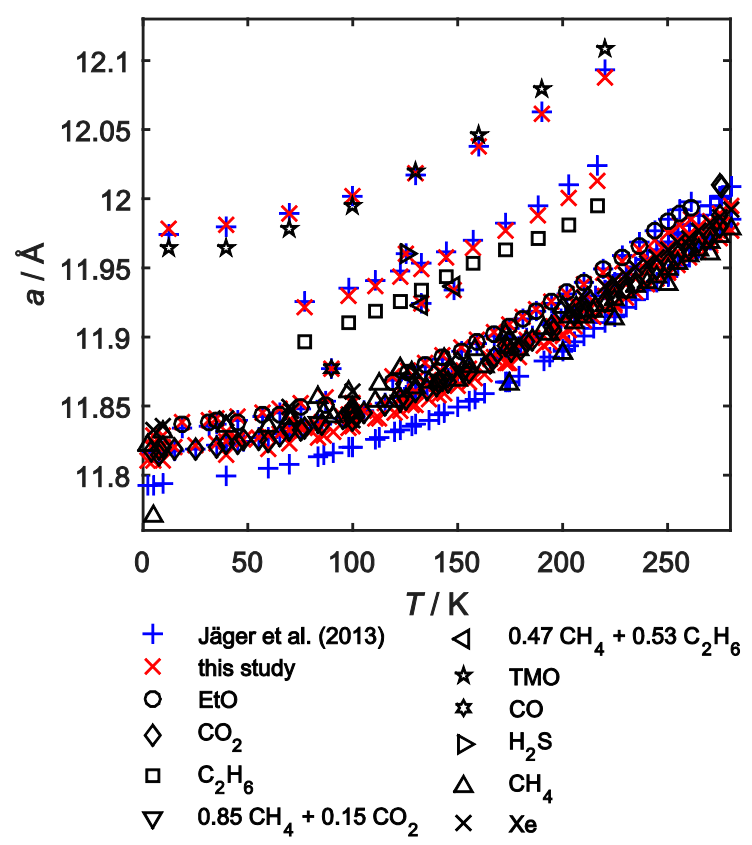

Fig. 1. Experimental data for the temperature dependence of the lattice parameter of sI gas hydrates at low pressures (typically at atmospheric pressure) compared to the correlation by Jäger et al. [1] and the new correlation.

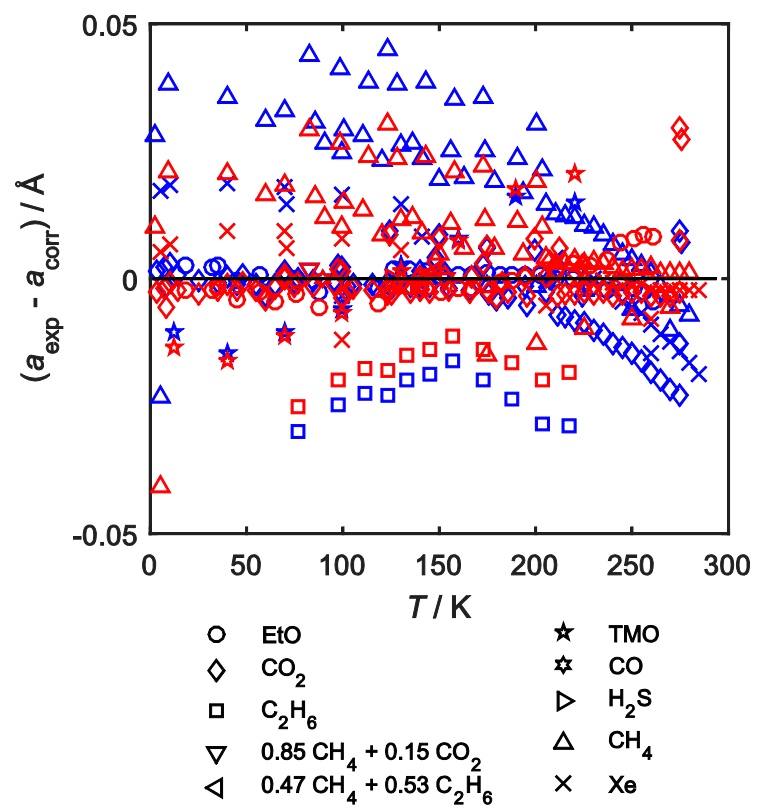

Fig. 2. Deviation of the correlation by Jäger et al. [13] (blue symbols) and the new correlation (red symbols) from the experimental data for the temperature dependence of the lattice parameter of sI gas hydrates at low pressures (typically at atmospheric pressure). 
In the low temperature region below $200 \mathrm{~K}$, both correlations provide relatively good reproduction of the experimental data. Larger deviations can be seen only by some data sets for methane and ethane hydrates caused by slight discrepancies between the temperature data sets and the pressure data sets of these gas hydrates. The new correlation provides significantly better reproduction of the high temperature data for $\mathrm{CO}_{2}, \mathrm{CH}_{4}$ and Xe hydrates by Hansen et al. [16] from 2016. As already shown in Table 3, the new correlation is in general in better agreement with the experimental data; see Fig. 2.

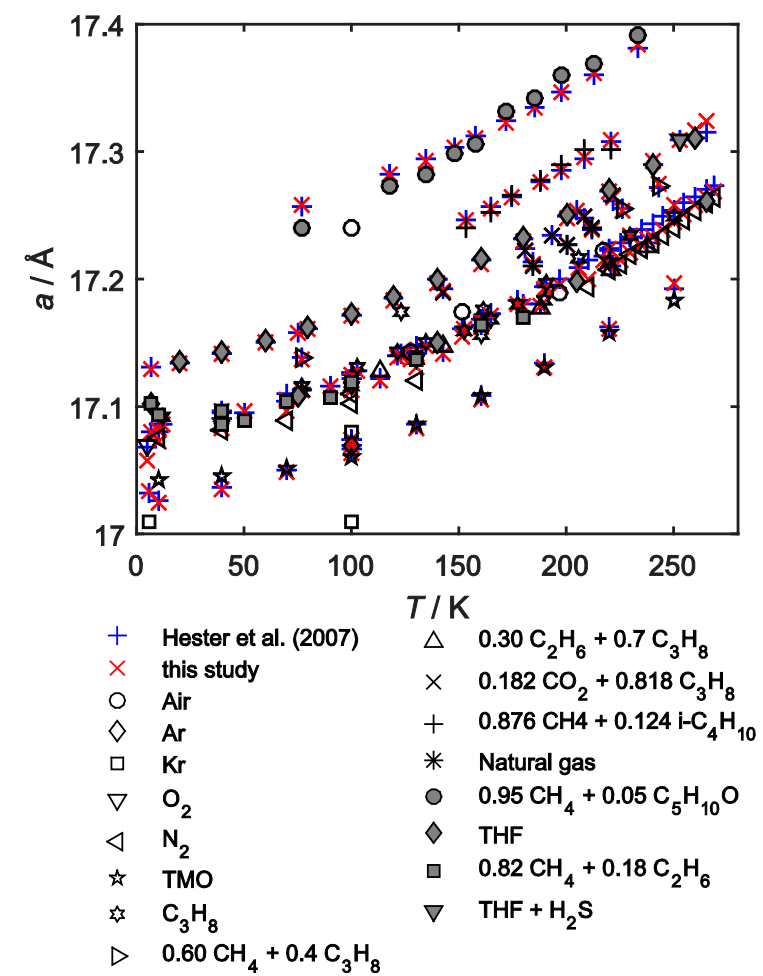

Fig. 3. Experimental data for the temperature dependence of the lattice parameter of sII gas hydrates at low pressures (typically at atmospheric pressure) compared to the correlation by Hester et al. [17] and the new correlation.

The experimental data for the temperature dependence of the lattice parameter for sII hydrates are compared to the correlation by Hester et al. [17] and the new correlation (12) in Fig. 3. The correlations provide very good reproduction of the experimental data over a wide temperature range. The differences between both correlations are almost negligible in this case, except for the new temperature data for nitrogen hydrates by Hansen et al. [16]. The new correlation is in much better agreement with these data compared to the correlation by Hester et al. [17]. The deviations of both correlations from the experimental data are shown in Fig. 4.

\subsection{Results - pressure dependence}

The pressure dependence of the lattice parameter for sI hydrates is shown in Fig. 5. The experimental data for four hydrate formers are compared with the correlation employed in the pure hydrate model [3] and with the new correlation (12).
At extremely high pressures above $500 \mathrm{MPa}$, the results of the new correlation are better for xenon hydrates while slightly worse for ethane hydrates compared to the original correlation [3]. As can be seen in Fig. 6 showing the deviations of both correlations from the experimental data, a noticeable improvement of the new correlation was achieved at pressures below $150 \mathrm{MPa}$. The new correlation agrees better with the data for methane hydrates and for xenon hydrates in this region.

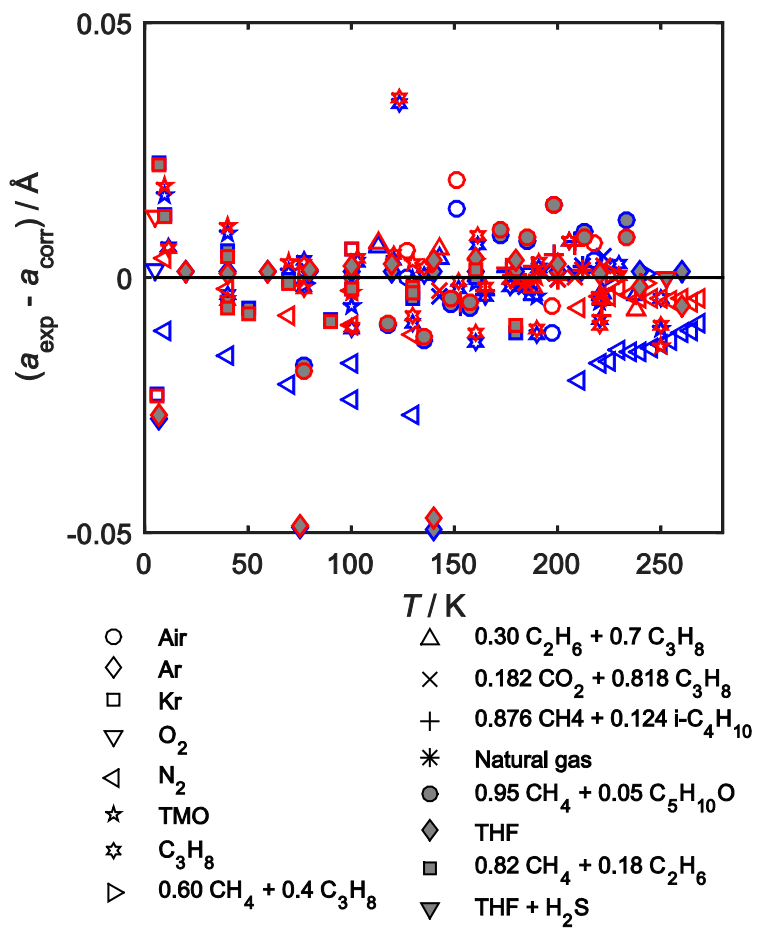

Fig. 4. Deviation of the correlation by Hester et al. [17] (blue symbols) and the new correlation (red symbols) from the experimental data for the temperature dependence of the lattice parameter of sII gas hydrates at low pressures (typically at atmospheric pressure).

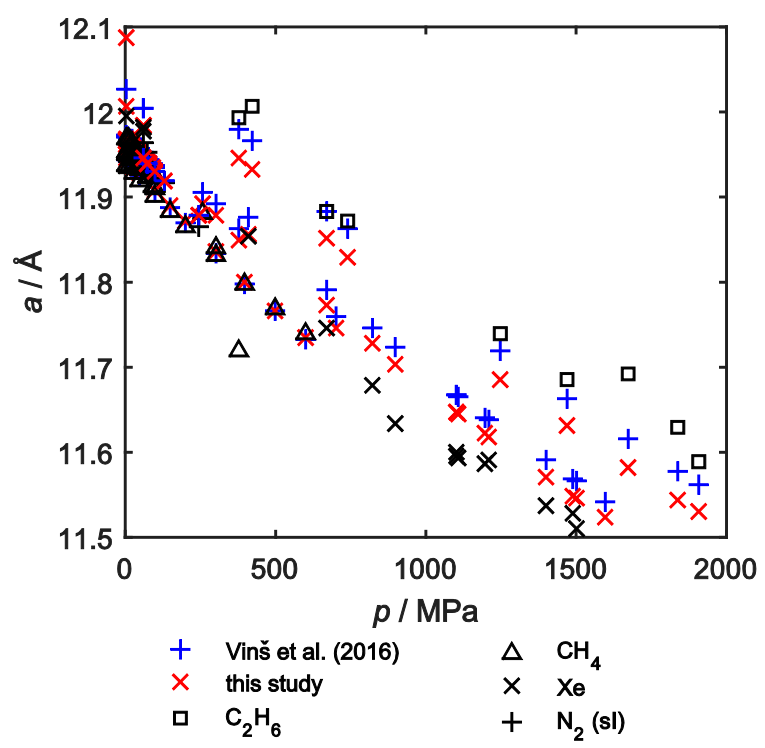

Fig. 5. Experimental data for the pressure dependence of the lattice parameter of sI gas hydrates compared to the correlation by Vinš et al. [3] and the new correlation. 


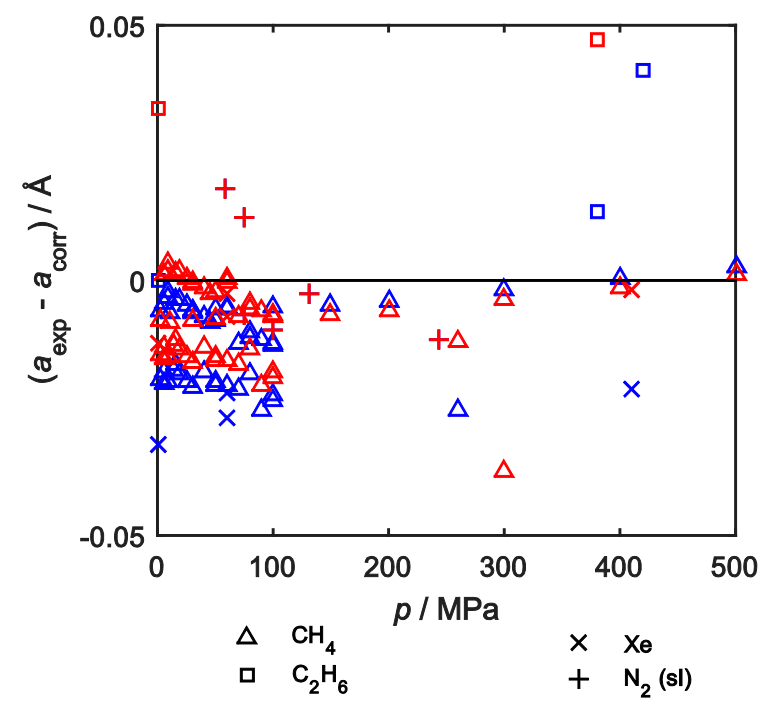

Fig. 6. Deviation of the correlation by Vinš et al. [3] (blue symbols) and the new correlation (red symbols) from the experimental data for the pressure dependence of the lattice parameter of sI gas hydrates.

Fig. 7 shows the pressure dependent data for the lattice parameter of sII hydrates. The two correlations provide comparable results, which are in good agreement with the experimental data in both cases. We note that the data for THF + Xe mixed hydrates up to $3 \mathrm{GPa}$ were considered in this study.

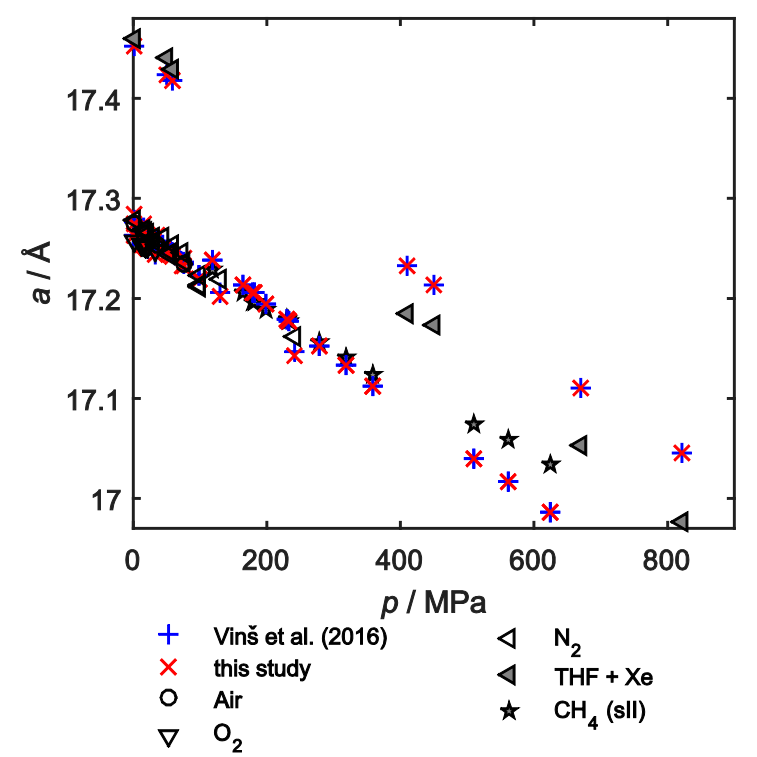

Fig. 7. Experimental data for the pressure dependence of the lattice parameter of sII gas hydrates compared to the correlation by Vinš et al. [3] and the new correlation.

\section{Conclusions}

The correlation for the temperature and pressure dependences of the lattice parameter of sI and sII gas hydrates developed in the previous study [3] was revised and modified such that it can be used for modeling of mixed hydrates. The new correlation was simultaneously fitted to the experimental data for both the temperature dependence and the pressure dependence of the hydrate volume using a two-stage Levenberg-Marquardt algorithm. A set of values for the thermal expansion coefficients $\alpha_{1}$ to $\alpha_{3}$ and for the reference lattice parameter $a_{0}$ was evaluated at the reference temperature of $273.15 \mathrm{~K}$ and the reference pressure of $1 \mathrm{~Pa}$. The bulk modulus was considered constant and equal to $10 \mathrm{GPa}$ (with $B_{0}^{\prime}=4$ ) for all selected hydrates.

The new model for the volume of sI and sII gas hydrates is in good agreement with the experimental data, including the recent data of Hansen et al. [16], over wide temperature and pressure ranges. Therefore, the universal modeling approach for sI and sII formers for the temperature dependence of the lattice parameter as proposed by Hester et al. [17] and for the pressure dependence as proposed by Vinš et al. [3] with the new parameters proposed in this work will be used for modeling mixed hydrates.

\section{List of abbreviations}

AAD absolute average deviation

$\mathrm{AD}$ average deviation

$\mathrm{Ar}$ argon

CCS carbon capture and storage

$\mathrm{CH}_{4}$ methane

$\mathrm{C}_{2} \mathrm{H}_{6} \quad$ ethane

$\mathrm{C}_{3} \mathrm{H}_{8} \quad$ propane

$\mathrm{C}_{5} \mathrm{H}_{10} \mathrm{O}$ tetrahydropyran

$\mathrm{CO} \quad$ carbon monoxide

$\mathrm{CO}_{2} \quad$ carbon dioxide

EtO ethylene oxide

$\mathrm{H}_{2} \mathrm{~S} \quad$ hydrogen sulphide

i- $\mathrm{C}_{4} \mathrm{H}_{10} \quad$ isobutane

$\mathrm{Kr} \quad$ krypton

$\mathrm{N}_{2} \quad$ nitrogen

$\mathrm{O}_{2} \quad$ oxygen

THF tetrahydrofuran

TMO trimethylene oxide

Xe xenon

\section{Acknowledgement}

The study was conducted with the financial help of the Czech Science Foundation grant GJ15-07129Y and the institutional support RVO:61388998.

\section{References}

1. E.D. Sloan, C.A. Koh, Clathrate Hydrates of Natural Gases, third ed. CRC Press, Taylor \& Francis Group, New York, USA, 2008

2. H. Li, J.P. Jakobsen, Ø. Wilhelmsen, J. Yan, Appl. Energy 88 3567-3579 (2011)

3. V. Vinš, A. Jäger, R. Span, J. Hrubý, Fluid Phase Equilib. 427, 268-281 (2016) 
4. V. Vinš, A. Jäger, J. Hrubý, R. Span, Fluid Phase Equilib. (2016) (submitted for publication)

5. A. Jäger, V. Vinš, R. Span, J. Hrubý, Fluid Phase Equilib. 429, 55-66 (2016)

6. J.H. van der Waals, J.C. Platteeuw, Clathrate solutions, Adv. Chem. Phys. 2 (1959) 1-57.

7. J. Gernert, R. Span, EOS-CG, J. Chem. Thermodyn. 93, 274-293 (2016)

8. O. Kunz, W. Wagner, J. Chem. Eng. Data 57, 30323091 (2012)

9. S. Hielscher, A. Jäger, V. Vinš, C. Breitkopf, J. Hrubý, R. Span, to be presented at Thermodynamik Kolloquium 2016, Technische Universität Kaiserslautern, Germany, October 5-7 (2016)

10. K. Levenberg, Q. Appl. Math. 2, 164 (1944)

11. D.W. Marquardt, J. Soc. Ind. Appl. Math. 11, 431 (1963)

12. A.L. Ballard, E.D. Sloan Jr., Fluid Phase Equilib. 194, 371-383 (2002)

13. A. Jäger, V. Vinš, J. Gernert, R. Span, J. Hrubý, Fluid Phase Equilib. 338, 100-113 (2013)

14. W.F. Kuhs, B. Chazallon, P.G. Radaelli, F. Pauer, J. Inclusion Phenom. 2965 (1997)

15. B. Chazallon, W.F. Kuhs, J. Chem. Phys. 117, 308$320(2002)$

16. T.C. Hansen, A. Falenty, W.F. Kuhs, J. Chem. Phys. 144, 054301 (2016)

17. K.C. Hester, Z. Huo, A.L. Ballard, C.A. Koh, K.T. Miller, E.D. Sloan, J. Phys. Chem. B 111, 88308835 (2007)

18. F.D. Murnaghan, Proc. Natl. Acad. Sci. U. S. A. 30 244-247 (1944)

19. F. Birch, Phys. Rev. 71, 809-824 (1947)

20. J.S. Tse, W.R. McKinnon, M. Marchi, J. Phys. Chem. 91, 4188-4193 (1987)

21. J.S. Tse, J. Phys. 48, 543-548 (1987)

22. T. Ikeda, O. Yamamuro, T. Matsuo, K. Mori, S. Torri, T. Kamiyama, F. Izumi, S. Ikeda, S. Mae, J. Phys. Chem. Solids 60, 1527-1529 (1999)

23. T. Ikeda, S. Mae, O. Yamamuro, T. Matsuo, S. Ikeda, R.M. Ibberson, J. Phys. Chem. A 104, 10623 (2000)

24. Z. Huo, M. Eaton, K.T. Miller, E.D. Sloan, Int. J. Thermophys. 26, 107-114 (2005)

25. K.A. Udachin, C.I. Ratcliffe, J.A. Ripmeester, J. Phys. Chem. B 105, 4200-4204 (2001)

26. S. Circone, L. A. Stern, S. H. Kirby, W. B. Durham, B. C. Chakoumakos, C. J. Rawn, A. J. Rondinone, Y. Ishii: J. Phys. Chem. B 107, 5529-5539 (2003)

27. A.Y. Manakov, A.Y. Likhacheva, V.A. Potemkin, A.G. Ogienko, A.V. Kurnosov, A.I. Ancharov, ChemPhysChem 12, 2476-2484 (2011)

28. A.J. Rondinone, B.C. Chakoumakos, C.J. Rawn, Y. Ishii, J. Phys. Chem. B 107, 6046-6050 (2003)

29. D.W. Davidson, M.A. Desando S.R. Gough, Y.P. Handa, C.I. Ratcliffe, J.A. Ripmeester, J.S. Tse, Nature 328, 418-419 (1987)

30. D. W. Davidson, Y. P. Handa, C. I. Ratcliffe, J. S. Tse, B. M. Powell, Nature 311, 142-143 (1984)

31. D.W. Davidson, S.K. Garg, S.R. Gough, Y.P. Handa, C.I. Ratcliffe, J.S. Tse and J.A. Ripmeester, J. Incl. Phenom. 2, 231-238 (1984)
32. C. Gutt, B. Asmussen, W. Press, M.R. Johnson, Y.P. Handa, J.S. Tse, J. Chem. Phys. 113, 4713-4721 (2000)

33. M.T. Kirchner, R. Boese, W.E. Billups, L.R. Norman, J. Am. Chem. Soc. 126, 9407-9412 (2004)

34. A.G. Ogienko, A.V. Kurnosov, A.Y. Manakov, E.G. Larinov, A.I. Ancharov, M.A. Sheromov, A.N. Nesterov, J. Phys. Chem. B 110, 2840-2846 (2006)

35. S. Takeya, M. Kida, H. Minami, H. Sakagami, A. Hachikubo, N. Takahashi, H. Shoji, V. Soloviev, K. Wallmann, N. Biebow, A. Obzhirov, A. Salomatin, J. Poort, Chem. Eng. Sci. 61, 2670-2674 (2006)

36. H. Docherty, A. Galindo, C. Vega, E. Sanz, J. Chem. Phys. 125, 074510 (2006)

37. A. Klapproth, E. Goreshnik, D. Staykova, H. Klein, W.F. Kuhs, Can. J. Phys. 81, 503-518 (2003)

38. H. Hirai, T. Kondo, M. Hasegawa, T. Yagi, Y. Yamamoto, T. Komai, K. Nagashima, M. Sakashita, H. Fujihisa, K. Aoki, J. Phys. Chem. B 104, 14291433 (2000)

39. C. Sanloup, H.-K. Mao, R. Hemley, J. Proc. Natl. Acad. Sci. U.S.A. 99, 25-28 (2002)

40. S. Takeya, H. Nagaya, T. Matsuyama, T. Hondoh, V.Y. Lipenkov, J. Phys. Chem. B 104, 668-670 (2000)

41. C.J. Rawn, A.J. Rondinone, B.C. Chakoumakos, S. Circone, L.A. Stern, S.H. Kirby, and Y. Ishii, Can. J. Phys. 81, 431-438 (2003)

42. C.Y. Jones, S.L. Marshall, B.C. Chakoumakos, C.J. Rawn, Y. Ishii, J. Phys. Chem. B 107, 6026-6031 (2003)

43. C.J. Rawn, A.J. Rondinone, B.C. Chakoumakos, S.L. Marshall, L.A. Stern, S. Circone, S.H. Kirby, C.Y. Jones, B.H. Toby, Y. Ishii, Proc. 4th Int. Conf. Gas Hydrates, Yokohama, Japan, May 19-23, 595598 (2002)

44. T.C.W. Mak, R.K. McMullan, J. Chem. Phys. 42, 2732-2737 (1965)

45. J. Shu, X. Chen, I.M. Chou, W. Yang, J. Hu, R.J. Hemley, H. Mao, Geosci. Front. 2, 93-100 (2011)

46. J.B. Klauda, S.I. Sandler, Ind. Eng. Chem. Res. 39, 3377-3386 (2000)

47. A. Martín, C.J. Peters, J. Phys. Chem. C 113, 422430 (2009) 